\title{
Different growing strategies of two winter wheat cultivars under rainfed conditions during dry years in North China Plain
}

\author{
Baodi Dong, Hong Yang, Yunzhou Qiao, Mingming Zhang, Yakai Wang, Lele Jin, Mengyu Liu* \\ (Key Laboratory of Agricultural Water Resources, Hebei Laboratory of Agricultural Water-Saving, \\ Center for Agricultural Resources Research, Institute of Genetics and Developmental Biology, Chinese Academy of Sciences, 286 \\ HuaizhongRoad, Shijiazhuang 050021, China)
}

\begin{abstract}
The North China Plain (NCP) is a severe water shortage region, especially during the wheat growing season. Understanding the response of grain yield and water availability in winter wheat cultivars (Triticum aestivum $\mathrm{L}$.) is important to adjust planting structure under groundwater reducible exploitation in rainfed dry years of NCP. Field experiments were conducted at the Luancheng Agroecosystem Experiment Station of the Chinese Academy of Sciences, Hebei, China. Two different drought resistant winter wheat cultivars (Jinmai47 and Shiluan02-1) were grown under rainfed conditions during four years of 2010-2011, 2011-2012, 2012-2013 and 2013-2014. Grain yield and its components, aboveground biomass (AB), dry matter accumulation translocation efficiency, water consumption, water use efficiency at field scale, and photosynthetic characteristics were measured. The results showed that Jinmai47 rapidly accumulated AB by higher tiller and photosynthetic potential comparing with those of Shiluan02-1. Its grain yield was $16.49 \%$ higher than that of the drought-sensitive winter wheat variety Shiluan02-1 during the four rainfed years. However, the dry matter remobilization efficiency (DMRE) and contribution of dry matter remobilization from heading stage to maturity stage to grain (CDMRE) of Shiluan02-1 was higher than those of Jinmai47. The average water use efficiency at grain yield level (WUEy), WUE at aboveground biomass level (WUEab), and WUE at grain yield under rainy conditions (WUEr) of Jinmai47 were $11.08 \%, 16.41 \%$, and $17.21 \%$ higher than those of Shiluan02-1. There was a significant difference in the WUEab and WUEr between the two wheat cultivars. The two wheat varieties under drought condition have different growing strategies. Jinmai47 has more tiller number, earlier vigor, and higher AB than Shiluan02-1, helping it to adapt to the fluctuations in the environment.
\end{abstract}

Keywords: winter wheat cultivar, grain yield, rainy treatment, water use efficiency, dry year DOI: $10.25165 /$ j.ijabe.20181105.4344

Citation: Dong B D, Yang H, Qiao Y Z, Zhang M M, Wang Y K, Jin L L, et al. Different growing strategies of two winter wheat cultivars under rainfed conditions during dry years in North China Plain. Int J Agric \& Biol Eng, 2018; 11(5): 150-159.

\section{Introduction}

Wheat is the second important cereals in China ${ }^{[1]}$. It is widely grown in the North China Plain (NCP). In 2014, the winter wheat cultivation area was 4.49 million hectares, accounting for nearly $18.65 \%$ of the total cultivated area in China. The total output of winter wheat was 2.89 million tons, contributing to more than $22.92 \%$ of total wheat output in China ${ }^{[2]}$. During recently years, the NCP is facing severe water shortage crisis. The mean precipitation here is approximately $500 \mathrm{~mm}$ a year ${ }^{[3]}$, mainly concentrated in summer (July-September). The long term (1990-2014) annual average precipitation during winter wheat

\section{Receive date: 2018-05-02 Accepted date: 2018-08-30}

Biographies: Baodi Dong, $\mathrm{PhD}$, Associate Professor, research interest: plant stress physiology, Email: dongbaodi@126.com; Hong Yang, PhD candidate, research interest: plant stress physiology, Email: yanghong215@, mails.ucas.ac.cn; Yunzhou Qiao, PhD, Associate Professor, research interest: climate change, Email: qiaoyunzhou@sjziam.ac.cn; Mingming Zhang, PhD, research interest: crop water management, Email: zhangmingming13@ mails.ucas.ac.cn; Yakai Wang, Master, research interest: plant stress physiology, Email:wangyakai.01@163.com; Lele Jin, Master, research interest: crop water management, Email: jinlele17@mails.ucas.ac.cn.

*Corresponding author: Mengyu Liu, Professor, research interest: efficient water utilization in crops and water saving technologies. Key Laboratory of Agricultural Water Resources, Hebei Key Laboratory of Water-Saving Agriculture, Center for Agricultural Resources Research, Institute of Genetics and Developmental Biology, Chinese Academy of Sciences, Shijiazhuang 050021, China. Tel: +86-311-85871562, Fax: +86-311-85815093, Email: mengyuliu2016@126.com. growing season (Oct.-Jun.) was $116.9 \mathrm{~mm}$ in the NCP, which only meets less than $40 \%$ of the wheat water consumption (320$550 \mathrm{~mm})^{[4]}$. The winter wheat relies mainly on groundwater extraction for high grain yield in this region ${ }^{[5]}$. Therefore, irrigation water use is largely responsible for the decline in groundwater level. Recently, the water table has been steadily declining by about $1 \mathrm{~m}$ a year in the $\mathrm{NCP}^{[6]}$. Over extraction of groundwater has resulted in a series of environmental problems, such as decrease in funnel land subsidence ${ }^{[7]}$. Water resource safety and ecological security are facing a huge challenge ${ }^{[8]}$.

To achieve reducible exploitation of groundwater, several measures to conserve water have been proposed. Since 2014, comprehensive treatment schemes for groundwater over pumping in Hebei Province have been implemented. These mainly included adjusting crop planting structure and promoting high yield and low-water consumption crops $^{[2]}$. In many regions, reducing wheat cultivated area and resting the soil for some months have been employed to achieve reducible exploitation. Furthermore, some studies have suggested that the wheat-maize (Zea mays L.) cropping system should be prohibited in the $\mathrm{NCP}^{[9]}$. Different cropping systems have been recommended, including annual spring maize or winter wheat-summer maize-spring maize thrice every two years ${ }^{[10]}$. However, in addition to agricultural and economic benefits, winter wheat also has ecological function as a winter cover. For example, if winter wheat cultivated area is reduced because of groundwater reducible-exploitation, the farmlands will be left uncovered, increasing sandstorms and sand blowing ${ }^{[2]}$. In $\mathrm{NCP}$, precipitation is low during the winter wheat growing season, 
while high precipitation occurs before winter wheat sown and therefore the soil moisture content is suitable to sow winter wheat and obtain some grain yield. In addition, many farmers have abandoned their farm and moved to cities in search of high income works. Therefore, there is seldom labor for fieldwork in rural area. Furthermore, crops irrigation is difficult due to deeper groundwater level and fewer water production of tube well. Therefore, it is necessary to promote rainfed agriculture with high grain yield ${ }^{[11]}$.

Several studies have recognized genetic variation in the water use efficiency (WUE) since the beginning of the 20th century ${ }^{[12-16]}$. Dong et al. ${ }^{[14]}$ reported that the winter wheat varieties can be divided into four types: high yield and high WUE, moderate yield and high WUE, moderate yield and moderate WUE, and low yield and low WUE. However, only a few studies have concentrated on the changes in the WUE of different cultivars under long-term rainfed condition in the NCP. The WUE is significantly affected by grain yield and drought tolerance under various deficit irrigation conditions $^{[6]}$. Nagy et al. ${ }^{[17]}$ showed markedly differences in water consumption among different drought-resistant crop varieties. Furthermore, the sensitive cultivars need more water than the drought-resistant cultivars. Studies have indicated that the main factors affecting grain yield are harvest index (HI) and aboveground biomass $(\mathrm{AB})^{[5]}$. However, other studies have reported that the $\mathrm{HI}$ is a more important factor than $\mathrm{AB}$ for grain yield. Further, water stress promotes the translocation of assimilates to grains. Plants have different strategies by morphologic and agronomic characters to survive various environmental stresses ${ }^{[18,19]}$. Due to complex interactions of mechanisms in response to water deficit during the growth and development of winter wheat, limited information is available on $\mathrm{AB}$ remobilization between resistant and sensitive wheat cultivars grown under rainfed conditions. Long-term experiments in rainfed fields are essential to characterize both constitutive and adaptive traits related to the WUE.

In the present study, two winter wheat cultivars were conducted to evaluate their response to rainfed condition in terms of crop yield and WUE at different levels (WUEy, WUEab and
WUEr) in the NCP. The study aimed to (1) investigate the effect of rainfed condition on grain yield, WUEy, WUEab and WUEr of the two types of cultivars, (2) determine the responses of different characteristics of the two wheat cultivars, and (3) analyze the ecological benefits of rainfed winter wheat. The results will provide valuable information on how to select wheat variety in groundwater reducible-exploitation.

\section{Materials and methods}

\subsection{Study site}

A field experiment was carried out during the wheat growing seasons from 2010 to 2014 at the Luancheng Agroecosystem Experimental Station at Shijiazhuang, Hebei Province in the NCP $\left(37^{\circ} 53 \mathrm{~N}\right.$ and $\left.114^{\circ} 40^{\prime} \mathrm{E}\right)$. The groundwater table of this area is about $50 \mathrm{~m}$ below the surface. The area is semi-humid with a monsoon climate. The annual mean temperature is $12.2^{\circ} \mathrm{C}$. The annual average evaporation was $1040 \mathrm{~mm}$ and the relative humidity was $65 \%$. The annual precipitation in the last 25 years was $500 \mathrm{~mm}$, with $70 \%$ annual precipitation after the harvest of winter wheat. The area is suitable for crop production, and wheat-maize double cropping system is common. Soil at the study area was a loam with a field capacity of $38.8 \%$, a permanent wilting point of $13 \%(\mathrm{v} / \mathrm{v})$, and a bulk density of $1.53 \mathrm{~g} / \mathrm{cm}^{3}$ for a $2-\mathrm{m}$ profile. Further, the nutrient contents in the $20-\mathrm{cm}$ surface soil were as follows: $15.7 \mathrm{~g} / \mathrm{kg}$ total organic matter, $102.9 \mathrm{mg} / \mathrm{kg}$ available nitrogen $(\mathrm{N}), 151.1 \mathrm{mg} / \mathrm{kg}$ available potassium $(\mathrm{K})$, and $33.9 \mathrm{mg} / \mathrm{kg}$ available phosphorus $(\mathrm{P})$.

\subsection{Experimental design and crop management}

The winter wheat (Triticum aestivum L.) cultivars Shiluan02-1 and Jinmai47 were cultivated in a large area in the NCP. Shiluan02-1 (9411/9430) is a high yield and relatively recent cultivar, released in 2004. It is suitable for high water and fertilized conditions, and is drought sensitive. Jinmai47 $(12057 / 522 / \mathrm{k} 37-20)$ is a drought-resistant cultivar, released in 1997. It is a dry-land control variety of Huanghuaihai wheat cultivated area. The characteristics of the two winter wheat cultivars are shown in Figure 1.

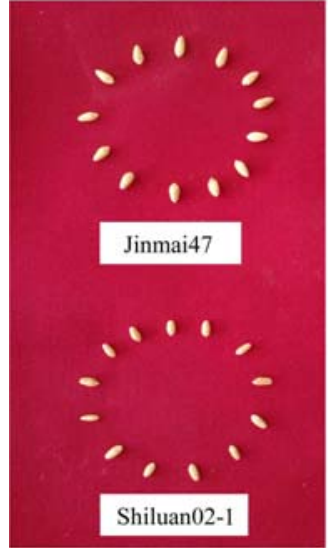

a. Seed

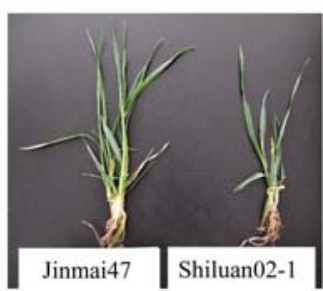

b. Tiller number

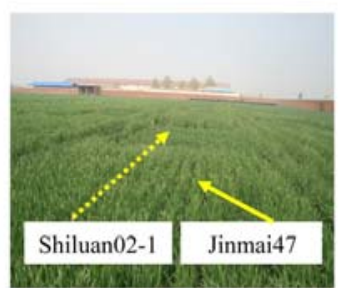

c. Growth in field

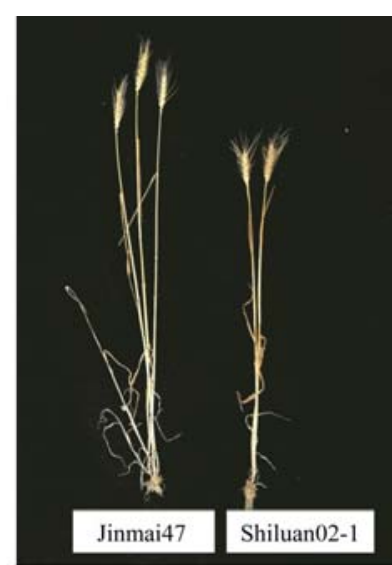

d. Single mature plant

Figure 1 Characteristics of the two winter wheat cultivars

Eight plots were laid out during the same growing season. Each plot was $8 \mathrm{~m} \times 6 \mathrm{~m}$ and was separated by $2-\mathrm{m}$ wide protection line. Each winter wheat cultivar was replicated four times. In every plot $2 \mathrm{~m}$ long aluminum tubes were installed to measure the soil water content at the center. Winter wheat was sown on October 8, 2010, October 13, 2011, October 10, 2012, and October 9,2013 , respectively. The winter wheat was harvested on June 6 , 2011, June 8, 2012, June 10, 2013 and June 5, 2014, respectively.
Before rotary tillage, the millet straws were laid on the fields, and base chemical fertilizers containing $\mathrm{N}$ and $\mathrm{P}$ were applied. The fertilizer rate applied was as follows: $200 \mathrm{~kg} / \mathrm{hm}^{2} \mathrm{~N}$ and $60 \mathrm{~kg} / \mathrm{hm}^{2}$ $\mathrm{P}$. There was no further addition of fertilizers and irrigation throughout the growing season. After winter wheat harvest, millet was sown after the first irrigation. Each irrigation was about $70 \mathrm{~mm}$. All the plots were under the same natural precipitation conditions during the four growing seasons. The main operating 
steps are presented in Table 1.

Table 1 Main operating steps followed during the 2010-2014 growing seasons

\begin{tabular}{cl}
\hline $\begin{array}{c}\text { Growing } \\
\text { season }\end{array}$ & \multicolumn{1}{c}{ Operating steps followed } \\
\hline & $\begin{array}{l}\text { Laying of millet straws on field, application of base fertilizer, rotary } \\
\text { tillage, preparation of ground and bordering of plantation, sowing of } \\
\text { seeds on October } 8-13 \text { using a 2BJM bevel-type precision seeder } \\
\text { (Laiwu Hualong Machinery Factory, China). }\end{array}$ \\
$2010-$ & $\begin{array}{l}\text { The sowing row spacing was } 20 \mathrm{~cm} \text {, no irrigation and no fertilizer } \\
\text { application, harvested on June 5-10, return of wheat straw to the } \\
\text { field, one-time irrigation (70 mm), rotary tillage, planting of millet. }\end{array}$ \\
& $\begin{array}{l}\text { Precipitation was } 291.9 \mathrm{~mm}, 344.3 \mathrm{~mm}, 484.2 \mathrm{~mm} \text { and } 461.5 \mathrm{~mm} \text { in } \\
\text { 2010, 2011, 2012 and } 2013, \text { respectively, between wheat harvest and } \\
\text { wheat planting in the subsequent growing season, millet harvested } \\
\text { on October1-5. }\end{array}$
\end{tabular}

\subsection{Materials and methods}

\subsubsection{Weather conditions}

Precipitation $(\mathrm{mm})$ and temperature $\left({ }^{\circ} \mathrm{C}\right)$ data used were recorded in an automatic standard weather station approximately $500 \mathrm{~m}$ away from the experimental site during the four growing seasons. The data are shown in Figure 2.

\subsubsection{Soil water content and water consumption}

The soil water content was measured using a neutron meter (CNC503B; Aozuo Ecology Instrumentation Ltd., Beijing, China) in every plot at $10-\mathrm{cm}$ intervals during sowing, wintering, recovery, jointing, heading, anthesis, filling, and maturity stages of winter wheat. Soil moisture was measured in the $150 \mathrm{~cm}$ soil profile since the effective root zone depth was in the first $150 \mathrm{~cm}$ of soil in NCP. The total water consumption (TWC, mm) by the two winter wheat cultivars was calculated as follows ${ }^{[20,21]}$.

$$
T W C=P+I+\Delta W-R-D
$$

where, $P$ is precipitation, $\mathrm{mm}, I$ is irrigation water, $\mathrm{mm} ; R$ is the runoff, $\mathrm{mm} ; D$ is water drainage, $\mathrm{mm}$, and $\Delta W$ is the sowing soil moisture minus the maturity soil moisture, $\mathrm{mm}$. During winter wheat growing season in 2010-2014, there was no irrigation, therefore $I$ was zero. Precipitation was only 47.5-87.7 mm during four winter wheat growing season, it was lower than the long-term average precipitation $116.9 \mathrm{~m}$, so the four experimental growing seasons were considered as dry years ${ }^{[22]}$. $R$ was also negligible. The soil water content indicated that there was no water drainage at the site across the four growing seasons, therefore, $D$ was also be ignored. Thus,

$$
T W C=P+\Delta W
$$

2.3.3 Crop growth, grain yield, aboveground biomass and photosynthetic remobilization

The heading date was recorded as the day when about $50 \%$ of ears in a plot were headed. Besides, maturity dates were also marked when there were no green ears. For aboveground biomass measurements, 50 stems were sampled randomly and were cut at the base during the heading and maturity stages from each plot. Plant density of the two wheat cultivars was recorded. During the maturity stage, all the wheat samples were divided into stems, leaves, sheath, glumes and grains. The samples were dried at $80^{\circ} \mathrm{C}$ to a constant weight. According to methods developed by $\mathrm{Chu}$ et al. ${ }^{[23]}$ and Sun et al. ${ }^{[24]}$, various parameters related to aboveground dry matter were calculated. Dry matter remobilization from heading stage to maturity stage (DMR, $\mathrm{kg} / \mathrm{hm}^{2}$ ) was measured using the following equation:

$$
D M R=D M H-D M M
$$

where, $D M H\left(\mathrm{~kg} / \mathrm{hm}^{2}\right)$ is the aboveground biomass during the heading stage; $D M M\left(\mathrm{~kg} / \mathrm{hm}^{2}\right)$ is the aboveground biomass of leaves, sheath, and glumes during maturity stage.
The dry matter remobilization efficiency (DMRE, \%) was calculated as follows:

$$
D M R E=\frac{D M R}{D M H} \times 100
$$

The contribution of dry matter remobilization from heading stage to maturity stage to grain (CDMRG, \%) was measured as follows:

$$
C D M R G=\frac{D M R}{G Y} \times 100
$$

For grain yield, at maturity in each experimental plot, 3 small samples of $2 \mathrm{~m}^{2}$ were selected randomly and harvested manually and air dried. Based on the collection data, the ear number (EN), kernel number per ear (KNP), aboveground biomass (AB), and harvest index (HI) were measured. The grain yield (GY) was obtained using a stationary thresher. The 1000-grain weight (TGW) was obtained using the mean weight of three 1000 grain samples.

\subsubsection{Photosynthetic characteristics}

The flag leaf photosynthetic characteristic was investigated using the Li-6400 portable photosynthesis system (LI-COR, Inc., USA). During the filling stage, the representative leaves were selected for the measurement from 10:00 to 12:00. During this time, the flow rate to the sample cells was $500 \mu \mathrm{mol} / \mathrm{s}$ and the leaf temperature was relatively stable, with an average of $25^{\circ} \mathrm{C} \pm 3^{\circ} \mathrm{C}$. In-chamber quantum sensor reaching the leaves was controlled between 0 and $1500 \mathrm{~mol} /\left(\mathrm{m}^{2} \cdot \mathrm{s}\right)$. Nine different light intensities were used, including $0,60,120,180,250,500,800,1200$ and 1500 $\mathrm{mol} /\left(\mathrm{m}^{2} \cdot \mathrm{s}\right)$. The photosynthesis rate was measured at 2-min intervals for each light intensity.

\subsubsection{Water use efficiency at different levels}

The WUE in grain yield level (WUEy, $\mathrm{kg} /\left(\mathrm{hm}^{2} \cdot \mathrm{mm}\right)$ ) was measured as GY divided by TWC during each winter wheat growing season. The WUE in aboveground biomass level (WUEab, $\mathrm{kg} /\left(\mathrm{hm}^{2} \cdot \mathrm{mm}\right)$ ) was calculated as $\mathrm{AB}$ at maturity stage divided by TWC at each growing season. The water use efficiency in grain yield level under rainy condition (WUEr, $\left.\mathrm{kg} /\left(\mathrm{hm}^{2} \cdot \mathrm{mm}\right)\right)$ was calculated as GY under rainy conditions divided by precipitation during the winter wheat growing season.

2.3.6 Statistical analysis

The statistical analyses were performed with the SPSS version 16.0 software (SPSS Inc., Chicago, Il, USA). The one-way analysis of variance (ANOVA) tested the difference in grain yield, aboveground biomass, water use, and water use efficiency at different levels. The mean values were compared by the least significant difference (LSD) $t$-test at $p<0.05$.

\section{Results}

\subsection{Weather conditions}

The monthly precipitation of 2010-2014 and long-term average from 1990 to 2014 are represented in Figure 2a. High precipitation was recorded in April and May during the four growing seasons. The total precipitation was $61.7 \mathrm{~mm}, 65.9 \mathrm{~mm}$, $87.7 \mathrm{~mm}$ and $47.5 \mathrm{~mm}$ in the 2010-2011, 2011-2012, 2012-2013 and 2013-2014 during wheat growing seasons, respectively. The mean total precipitation from 2011 to 2014 was $65.7 \mathrm{~mm}$. Because the long-term average precipitation in recent 25 growing seasons was $116.9 \mathrm{~mm}$, the experimental growing seasons was considered as dry years ${ }^{[22]}$. Figure $2 b$ showed the daily air temperature at the experimental sites from October 1 to June 1 next year during the four growing seasons. The trend in temperature 
variation was similar during the four growing seasons (Figure $2 b$ ). The mean temperature in June was higher than that in other months. The lowest mean temperature was recorded in January. The lowest mean temperature in 2013-2014 was higher than that during the other three growing seasons (Figure 2b).

\subsection{Soil water content at sowing}

Under drought rainfed conditions, emergence rate is important for grain yield of winter wheat. And soil water content at sowing is significantly related to emergence rate. Figure 3 shows the soil water content in the $0-150 \mathrm{~cm}$ soil layer at sowing of the two wheat cultivars in 2010, 2011, 2012 and 2013, respectively. The trend of soil water content change of the two wheat cultivars was similar during four growing seasons. The soil water content in the 0 $40 \mathrm{~cm}$ soil layer was lower than that in the $40-150 \mathrm{~cm}$ during the four growing seasons, especially in 2012-2013 and 2013-2014 growing seasons. Because much more precipitation was stored in the soil than in 2010-2011 and 2011-2012 during wheat harvested and wheat sown in the subsequent growing season (Table 1), the soil water content at sowing in the $40-150 \mathrm{~cm}$ soil layer increased significantly. Furthermore, the fluctuation amplitude of soil water

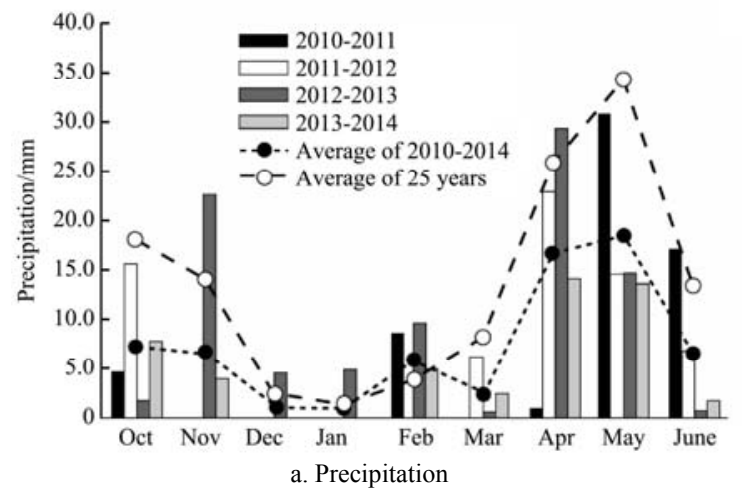

content during the four growing seasons was marginally different between the two wheat cultivars. The range of soil water content in the $0-150 \mathrm{~cm}$ before sowing in Jinmai47 was $20.54 \%-25.67 \%$, $21.93 \%-25.85 \%, 19.92 \%-29.08 \%$ and $22.19 \%-33.03 \%$ in $2010-$ 2011, 2011-2012, 2012-2013 and 2013-2014, respectively. The soil water content within the $0-150 \mathrm{~cm}$ before sowing in Shiluan02-1 was $19.83 \%-26.52 \%, \quad 22.92 \%-27.52 \%, \quad 17.66 \%-29.50 \%$ and $21.76 \%-34.08 \%$ in $2010-2011,2011-2012,2012-2013$ and $2013-$ 2014, respectively. In 2010-2011 and 2011-2012, the mean soil water content before sowing in Shiluan02-1 was higher than that of Jinmai47 due to difference in basic soil moisture. The water content showed a significant difference between the two wheat cultivars in the $60-110 \mathrm{~cm}$ soil layer before sowing in $2010-2011$ and 2011-2012. However, after four years of continuous rainfed cultivation, the soil water content of Shiluan02-1 was lower than that of Jinmai47. Furthermore, a significant difference was found in the $100-140 \mathrm{~cm}$ of soil. At the same growing seasons, precipitation is the same for the different plot. Soil moisture differences at sowing might be attributed to the difference in water consumption of two winter wheat cultivars and millet.

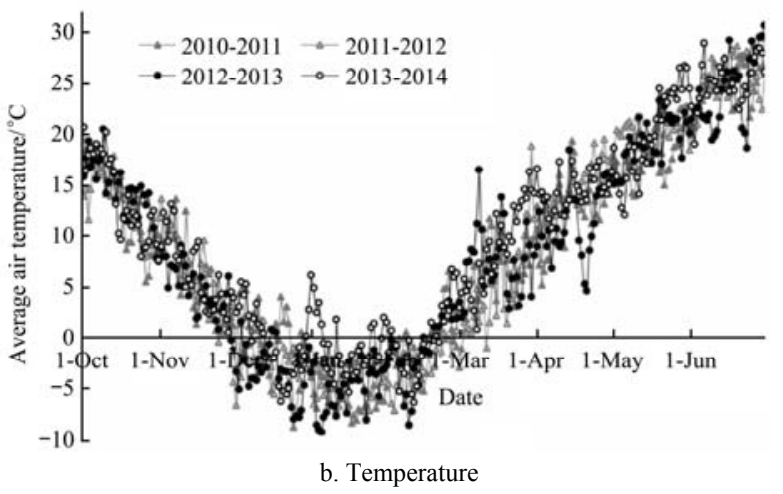

Figure 2 Precipitation and temperature at the experimental sites from 2010 to 2014
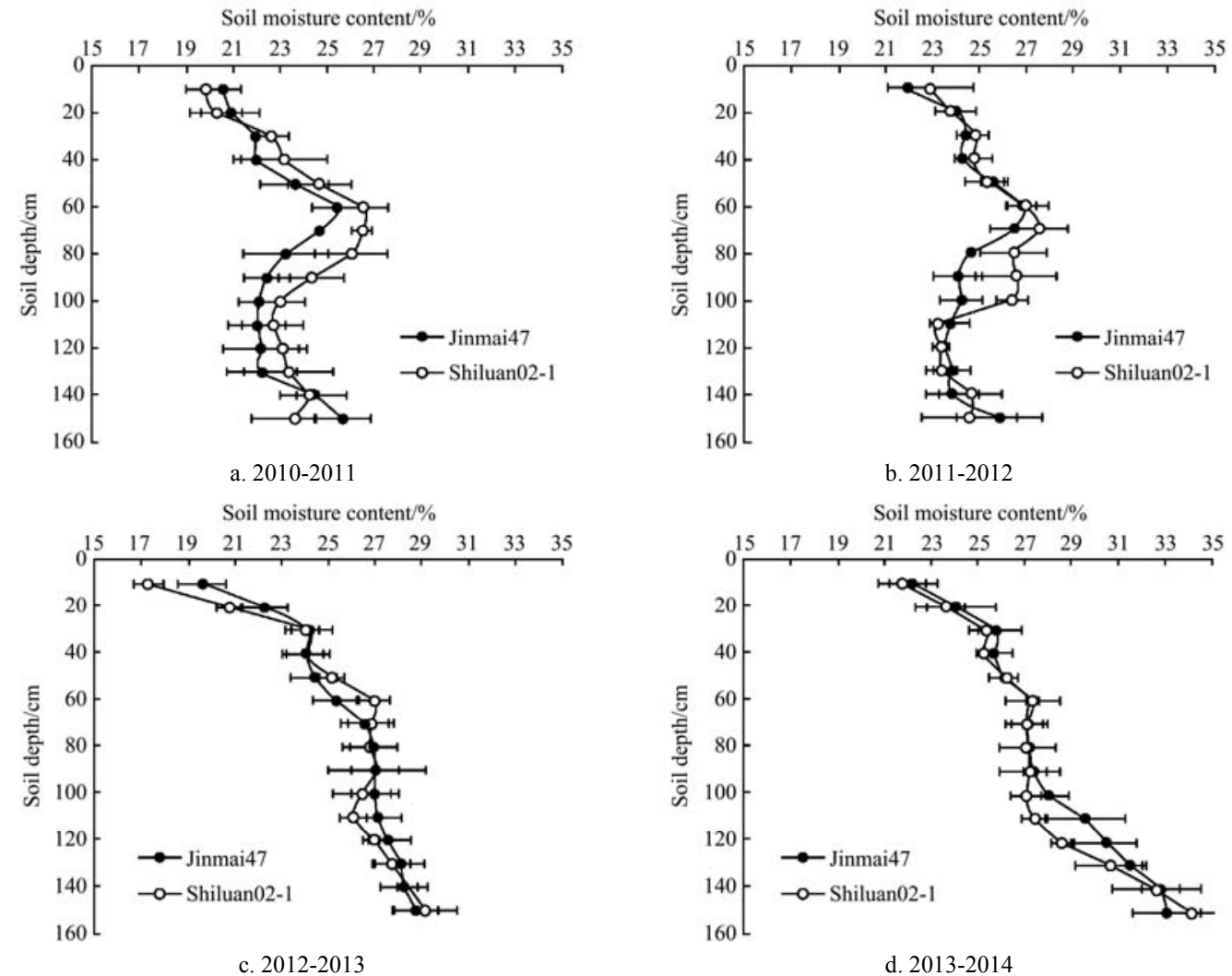

Note: The horizontal bars represent standard error.

Figure 3 Variation of soil water content in different depths of soil at sowing for different years 


\subsection{Photosynthesis-light response curve across years}

The photosynthesis-light response curve effectively reflects the photosynthetic characteristics of plants. The trends in photosynthesis-light response curve of the two varieties in 2010-2011, 2011-2012, 2012-2013 and 2013-2014 are summarized in Figure 4. The data obtained during the 4-years study period showed that the flag leaf of Jinmai47 and Shiluan02-1 exhibited a similar trend of the light response curves. The response curves of photosynthetic rate of flag leaf showed a decrease in upward tendency. When the light intensity was $0-250 \mu \mathrm{mol} /\left(\mathrm{m}^{2} \cdot \mathrm{s}\right)$. The maximum photosynthetic rate and the response curve slope of
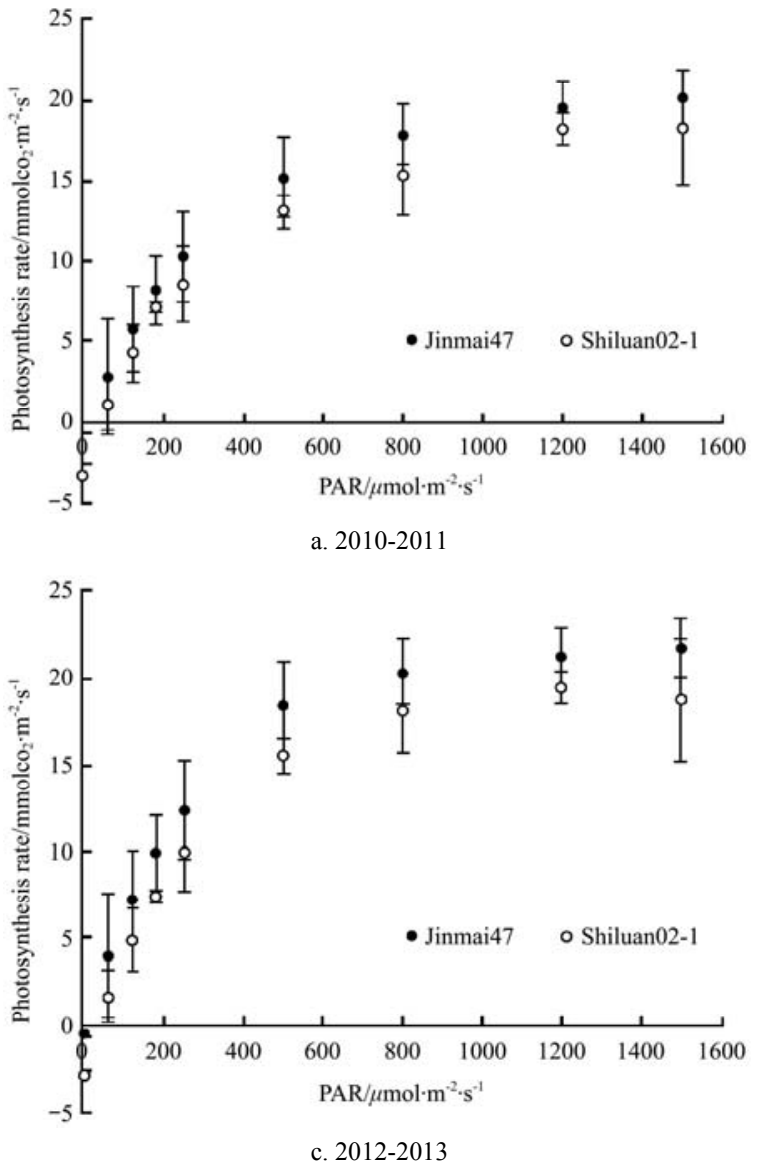

Note: The horizontal bars represent standard error.

Figure 4 Variation of photosynthesis rate to light of two wheat cultivars during grain filling stage from 2010 to 2014

\subsection{Plant height (PH)}

As shown in Figure 5, a significant difference was observed in the height of the two cultivars during the four growing seasons. Among the four growing seasons, for the wheat cultivar Jinmai47, the plant height in 2014 was significantly higher than that in the other three growing seasons. In 2014, the height of Jinmai47 was $32.63 \mathrm{~cm}$ higher than that of Shiluan02-1. One of the main reasons might be the high precipitation between wheat harvest and wheat sowing in the subsequent growing season in 2013 and higher growth rate of Jinmai47 (Table 1). The height of Jinmai47 was significantly higher than that of Shiluan02-1 irrespective of the four growing seasons. The average height of Jinmai47 was $73.74 \mathrm{~cm}$, which was $39.94 \%$ higher than that of Shiluan02-1. This indicated the obvious effect of different growing seasons on the height of Jinmai47 and Shiluan02-1. This effect was more significant in Jinmai47 than in Shiluan02-1, indicating that Jinmai47 has characteristic related to fast growth, under rainy conditions.
Jinmai47 were significantly higher and steep than those of Shiluan02-1 during the four growing seasons. With increase in the light intensity $\left(\mathrm{PAR}>250 \mu \mathrm{mol} /\left(\mathrm{m}^{2} \cdot \mathrm{s}\right)\right)$, the photosynthetic rate slowly increased. However, the maximal photosynthetic rate of Jinmai47 was always higher than that of Shiluan02-1. At the same PAR, the differences in photosynthetic rate between the two wheat cultivars were as follows: 2012-2013 > 2013-2014 > 2010-2011 > 2011-2012. Figure 4 indicated that the photosynthetic capacity of flag leaf of Jinmai47 was higher than that of Shiluan02-1.

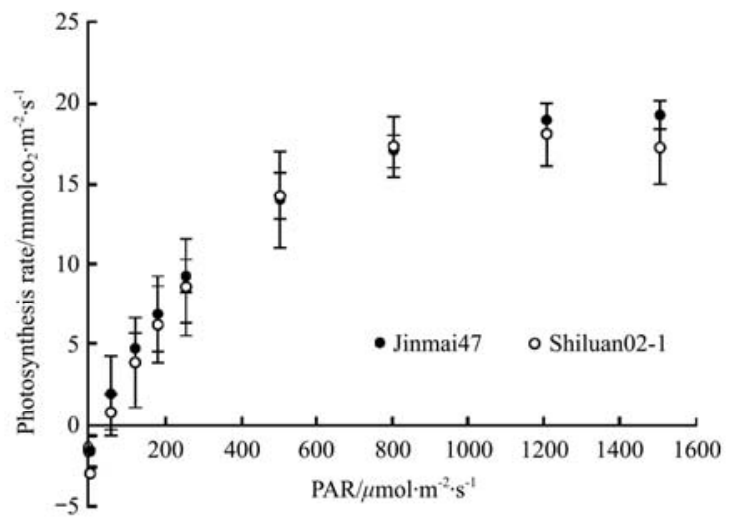

b. $2011-2012$

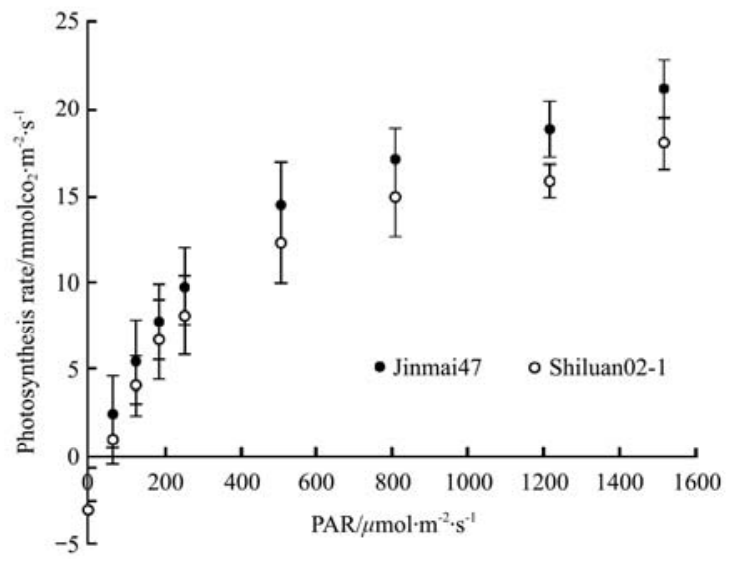

d. 2013-2014

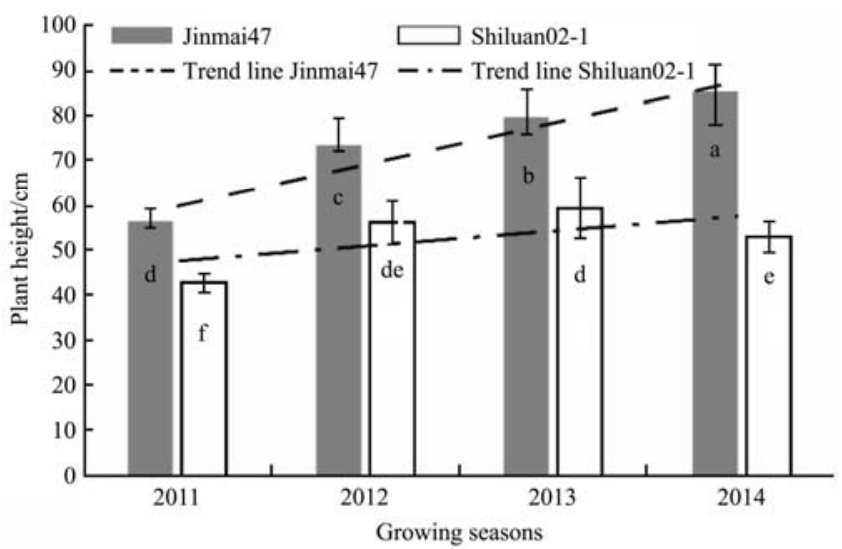

Note: The bars represent the least significant difference at $p \leq 0.05$.

Figure 5 Height of the two cultivars during different growing seasons under rainy conditions

\subsection{Dry matter remobilization}

The AB accumulation and remobilization varied with different 
cultivars and growing seasons (Table 2). During the heading stage, the DMH of Jinmai47 was higher than that of Shiluan02-1 during the four growing seasons. The average DMH of Jinmai47 was $5924.63 \mathrm{~kg} / \mathrm{hm}^{2}$, which was $14.32 \%$ higher than that of Shiluan02-1. The ANOVA showed that the difference in DMH during 2012-2013 and 2013-2014 reached the 5\% significance level. The DMM exhibited a trend similar to that of the DMH. The DMM of Jinmai47 was higher than that of Shiluan02-1 in every growing season, especially in 2012-2013 and 2013-2014. However, the DMR exhibited a tendency contrary to that of the DMH and DMM. The DMR of Jinmai47 was lower than that of Shiluan02-1. The DMR of Shiluan02-1 in 2013-2014 was the highest and that of Jinmai47 in 2010-2011 was the lowest. However, it did not exhibit significant difference between the two winter wheat cultivars in 2010-2011 and 2011-2012 (Table 2).
The DMRE of Shiluan02-1 was $64.32 \%$ higher than that of Jinmai47. The highest DMRE was observed in Shiluan02-1 during the 2013-2014 growing season (27.03\%), whereas the lowest DMRE was found in Jinmai47 during the 2010-2011 growing season. The highest CDMRG was observed in Shiluan02-1 during the first growing season. Jinmai47 presented the lowest CDMRG in 2013-2014. The CDMRG of Shiluan02-1 was $119.16 \%, 1.00 \%, 53.80 \%$ and $170.63 \%$ higher than that of Jinmai47 in 2010-2011, 2011-2012, 2012-2013 and 2013-2014, respectively. The dry matter remobilization indicates that Shiluan02-1 has a response strategy by rapid translocation of the DMH to grain under rainfed conditions, whereas the total biomass of Shiluan02-1 was lower than that of Jinmai47. It also suggested that Jinmai47 has stronger assimilation ability than Shiluan02-1 after heading stage with decrease in soil water content.

Table 2 Aboveground biomass accumulation and remobilization, remobilization efficiency, and contribution of dry matter pre-heading to grain in the two cultivars

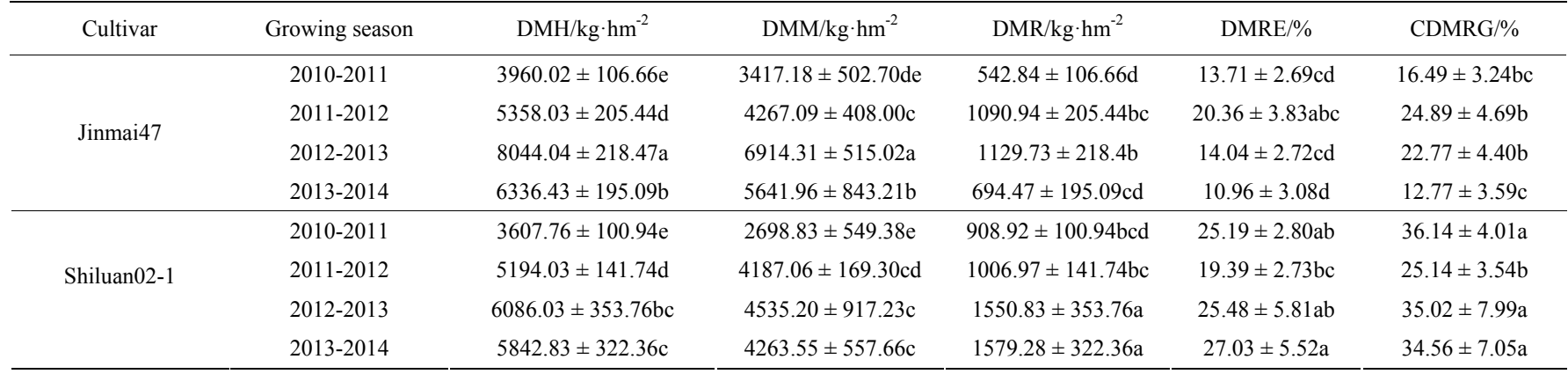

Note: DMH: dry matter at heading; DMM: dry matter of leaves, sheath, and glumes at maturity; DMR: dry matter remobilization from heading stage to maturity stage; DMRE: dry matter remobilization efficiency; CDMRG: contribution of dry matter remobilization from heading stage to maturity stage to grain (CDMRG). Values followed by different letter(s) in each column are significant $(p<0.05)$.

\subsection{Grain yield}

Significant differences in grain yield were observed during the four years between the two winter wheat cultivars $(p<0.01)$ (Table 3). The grain yield during the four years ranged from $2515.26 \mathrm{~kg} / \mathrm{hm}^{2}$ to $5437.96 \mathrm{~kg} / \mathrm{hm}^{2}$. The mean grain yield of Jinmai47 was $4519.05 \mathrm{~kg} / \mathrm{hm}^{2}$, which was $16.49 \%$ higher than that of Shiluan02-1 (3879.48 kg/hm²) (Table 4). The higher winter wheat yield was observed in 2012-2013 and 2013-2014. The grain yield of Jinmai47 was $30.89 \%, 9.44 \%, 12.08 \%$ and $19.00 \%$ higher than that of Shiluan02-1, respectively during the four growing seasons. The grain yield was not significantly different between the two cultivars in 2011-2012. Both received considerable amounts of precipitation $(61.7 \mathrm{~mm}$ and $65.9 \mathrm{~mm}$, respectively) during 2010-2011 and 2011-2012; however, there were significant differences in grain yields between two growing seasons. This is because of higher precipitation in the jointing and booting stages in 2011-2012 than in 2010-2011 (Figure 2). Furthermore, there was high soil water content before sowing in 2012-2013 and 2013-2014 because of high precipitation after the harvest of wheat (Table 1). So, the grain yield of two cultivars was much higher in 2012-2013 and 2013-2014 than in 2010-2011 and 2011-2012. The results suggest that drought tolerance plays an important role in wheat yield improvement in dry years.

This study also found that there was a significant difference in the EN, KNP, TGW, AB (Table 3). During the four different growing seasons, the $\mathrm{EN}, \mathrm{AB}$, and TGW of Jinmai47 were higher than those of Shiluan02-1, whereas the KNP of Jinmai47 was lower than that of Shiluan02-1. During the four growing seasons, the $\mathrm{AB}$ of Jinmai47 was $6709.40-11876.86 \mathrm{~kg} / \mathrm{hm}^{2}$ and that of Shiluan02-1 was 5214.09-8963.07 kg/hm². The AB of Jinmai47 was $28.68 \%, 5.59 \%, 32.51 \%$ and $25.44 \%$ higher than that of Shiluan02-1 during the four growing seasons, respectively. The EN of Jinmai47 was $10.76 \%, 6.55 \%, 0.78 \%$ and $7.13 \%$ higher than that of Shiluan02-1 during the four years, respectively. The KNP of the two cultivars was 26.75-31.27 grain/ear. The KNP of Jinmai47 was lower than that of Shiluan02-1. However, the TGW of Jinmai47 was significantly higher than that of Shiluan02-1 during the four growing seasons. There was a significant difference between the two winter wheat cultivars. In addition, the $\mathrm{HI}$ of the two winter wheat cultivars exhibited no significant difference, except in Jinmai47 during 2012-2013. The results suggest that the difference in grain yield between the two wheat cultivars might be due to the difference in $\mathrm{AB}$ and TGW.

Table 3 Variance analysis of grain yield (GY), aboveground biomass (AB), ear number (EN), kernel number per spike (KNP), 1000-grains weight (TGW), harvest index (HI), and water use efficiency (WUE) at different years (Y) and in different cultivars (C)

\begin{tabular}{ccccccccccc}
\hline Effect & GY & AB & EN & KNP & TGW & HI & WUEy & WUEab & WUEr \\
\hline $\mathrm{Y}$ & $<0.0001$ & $<0.0001$ & $<0.0001$ & $<0.0001$ & $<0.0001$ & 0.014 & $<0.0001$ & $<0.0001$ & $<0.0001$ \\
$\mathrm{C}$ & $<0.0001$ & $<0.0001$ & 0.823 & 0.182 & $<0.0001$ & 0.119 & 0.823 & $<0.0001$ & $<0.0001$ \\
$\mathrm{Y} \times \mathrm{C}$ & 0.562 & 0.012 & 0.003 & 0.019 & 0.01 & 0.03 & 0.003 & 0.029 & 0.071 \\
\hline
\end{tabular}


Table 4 Grain yield (GY), ear number (EN), kernel number per spike (KNP), 1000-grains weight (TGW), aboveground biomass (AB), and harvest index (HI) of the two cultivars during the four wheat growing seasons

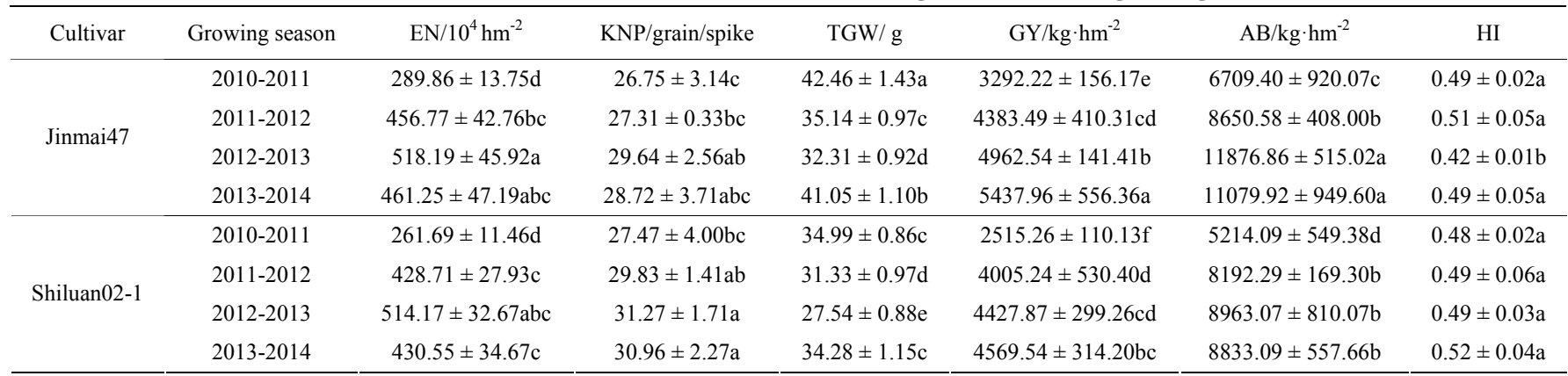

Note: Values followed by different letter(s) in each column are significant $(p<0.05)$

\subsection{Water consumption and water use efficiency at different levels}

The data in Table 5 showed that there were differences in water consumption, WUEy, WUEab, and WUEr between the two winter wheat cultivars. The WUEy was significantly affected by year and the interaction between year and cultivars (Table 3 ). The WUEab and WUEr were influenced by year and cultivars $(p<$ 0.0001) (Table 3). The WUEy, WUEab, and WUEr values ranged from $15.30 \mathrm{~kg} /\left(\mathrm{hm}^{2} \cdot \mathrm{mm}\right)$ to $26.12 \mathrm{~kg} /\left(\mathrm{hm}^{2} \cdot \mathrm{mm}\right), 31.72 \mathrm{~kg} /\left(\mathrm{hm}^{2} \cdot \mathrm{mm}\right)$ to $53.22 \mathrm{~kg} /\left(\mathrm{hm}^{2} \cdot \mathrm{mm}\right)$, and $40.77 \mathrm{~kg} /\left(\mathrm{hm}^{2} \cdot \mathrm{mm}\right)$ to $114.48 \mathrm{~kg} /\left(\mathrm{hm}^{2} \cdot \mathrm{mm}\right)$, respectively during the four years. Water consumption by the two winter wheat cultivars ranged from $164.36 \mathrm{~mm}$ to $225.76 \mathrm{~mm}$ during the dry growing seasons. The values were significantly lower than those in the normal and wet years. Water consumption in 2010-2011 was significantly lower than that in 2011-2012, 2012-2013, and 2013-2014. Water consumption in the same growing season was not significantly different for two cultivars, except in 2013-2014. The WUEy between the two cultivars was not significantly different, except in 2010-2011, during the same growing season, whereas the WUEab and WUEr were apparently different between the two cultivars. The WUEy, WUEab, and WUEr in 2010-2011 were significantly lower than those in 2011-2012, 2012-2013, and 2013-2014 for the two winter wheat cultivars because of the low $\mathrm{AB}$ and grain yield. The WUEy, WUEab, and WUEr of Jinmai47 were higher than those of Shiluan02-1 during all four growing seasons. The WUEy of Jinmai47 increased by $30.58 \%, 7.40 \%, 7.04 \%$, and $5.43 \%$, respectively during the four growing reasons, when compared with that of Shiluan02-1. There was a similar trend in the WUEab and WUEr. The WUEab increased by $28.33 \%, 3.56 \%, 26.56 \%$, and $11.15 \%$, respectively during the four growing seasons, when compared with that of Shiluan02-1. The WUEr of Jinmai47 was $30.89 \%, 9.44 \%, 12.08 \%$, and $19.00 \%$ higher than that of Shiluan $02-1$ during all four growing seasons, respectively. These findings indicate that selecting drought-resistant variety is important to improve crop water use efficiency in rainfed fields in the NCP.

Table 5 Water consumption, precipitation, WUEy, WUEab and WUEr of the two cultivars during the four wheat growing seasons

\begin{tabular}{|c|c|c|c|c|c|c|}
\hline Cultivar & Growing season & Total water consumption $/ \mathrm{mm}$ & Precipitation $/ \mathrm{mm}$ & WUEy $/ \mathrm{kg} \cdot\left(\mathrm{hm}^{2} \cdot \mathrm{mm}\right)$ & WUEab $/ \mathrm{kg} \cdot\left(\mathrm{hm}^{2} \cdot \mathrm{mm}\right)$ & $\mathrm{WUEr} / \mathrm{kg} \cdot\left(\mathrm{hm}^{2} \cdot \mathrm{mm}\right)$ \\
\hline \multirow{4}{*}{ Jinmai47 } & $2010-2011$ & $164.81 \pm 6.51 \mathrm{~d}$ & 61.7 & $19.98 \pm 0.95 b$ & $40.71 \pm 5.58 \mathrm{c}$ & $53.36 \pm 2.53 \mathrm{de}$ \\
\hline & 2011-2012 & $195.82 \pm 7.72 \mathrm{bc}$ & 65.9 & $22.38 \pm 2.10 b$ & $44.17 \pm 2.08 b c$ & $66.52 \pm 6.23 \mathrm{c}$ \\
\hline & $2012-2013$ & $225.76 \pm 9.07 \mathrm{a}$ & 87.7 & $21.98 \pm 0.63 b$ & $52.61 \pm 2.28 \mathrm{a}$ & $56.59 \pm 1.61 \mathrm{de}$ \\
\hline & $2013-2014$ & $208.21 \pm 14.50 \mathrm{ab}$ & 47.5 & $26.12 \pm 2.67 \mathrm{a}$ & $53.22 \pm 4.30 \mathrm{a}$ & $114.48 \pm 11.71 \mathrm{a}$ \\
\hline \multirow{3}{*}{ Shiluan02-1 } & $2010-2011$ & $164.36 \pm 14.46 \mathrm{~d}$ & 61.7 & $15.30 \pm 0.67 \mathrm{c}$ & $31.72 \pm 3.34 d$ & $40.77 \pm 1.78 \mathrm{f}$ \\
\hline & $2012-2013$ & $215.63 \pm 10.83 \mathrm{a}$ & 87.7 & $20.53 \pm 1.39 b$ & $41.57 \pm 3.76 \mathrm{c}$ & $50.49 \pm 3.41 \mathrm{e}$ \\
\hline & 2013-2014 & $184.47 \pm 6.30 \mathrm{c}$ & 47.5 & $24.77 \pm 1.70 \mathrm{a}$ & $47.88 \pm 3.02 b$ & $96.20 \pm 6.61 b$ \\
\hline
\end{tabular}

Note: Values followed by different letter (s) in each column are significant $(p<0.05)$.

\subsection{Correlation analysis}

There was a similar trend between the two wheat cultivars. Significant positive correlations were found between plant height and $\mathrm{AB}$ (Figure 6a) $\left(R^{2}=0.63\right.$, Shiluan02-1, $p<0.01 ; R^{2}=0.62$, Jinmai47, $p<0.01)$. The correlation analysis also indicated that the WUEy strongly positively related with grain yield under rainfed conditions (Figure 6c) $\left(R^{2}=0.81\right.$, Shiluan02-1, $p<0.01 ; R^{2}=0.73$, Jinmai47, $p<0.01)$. Moreover, there was significant positive relationship between the $\mathrm{AB}$ and WUEab under rainfed conditions (Figure 6d) $\left(R^{2}=0.81\right.$, Shiluan02-1, $p<0.01 ; R^{2}=0.89$, Jinmai47, $p<0.01$ ). As shown in the quadratic curve (Figure $6 \mathrm{~b}$ ), grain yield correlated with the $\mathrm{AB}\left(R^{2}=0.84\right.$ and 0.86 in Jinmai47 and Shiluan02-1, respectively, $p<0.01)$.

\section{Discussion}

The present study evaluated two different winter wheat cultivars, which showed contrast physiological and ecological responses under continuous rainfed conditions in the NCP. The grain yield, $\mathrm{AB}$, WUE, and associated characteristics, help understand the coping strategies of different drought-resistant Jinmai47 and Shiluan02-1. Therefore, the study will provide a new idea for the government sectorto adjust the structure of plantation.

\subsection{Grain yield of two wheat varieties under rainfed conditions in NCP}

With increase in water shortage and decrease in rural agricultural work, there is an urgent need to develop rainfed agriculture in the NCP. In the present study, the average grain yield of Jinmai47 and Shiluan02-1 was $3879.48 \mathrm{~kg} / \mathrm{hm}^{2}$ and $4519.05 \mathrm{~kg} / \mathrm{hm}^{2}$, respectively (Table 4), which is higher than that of the winter wheat Shanxi in dryland ${ }^{[25]}$. The grain yield of the drought-resistant wheat cultivar Jinmai47 was higher than that of 


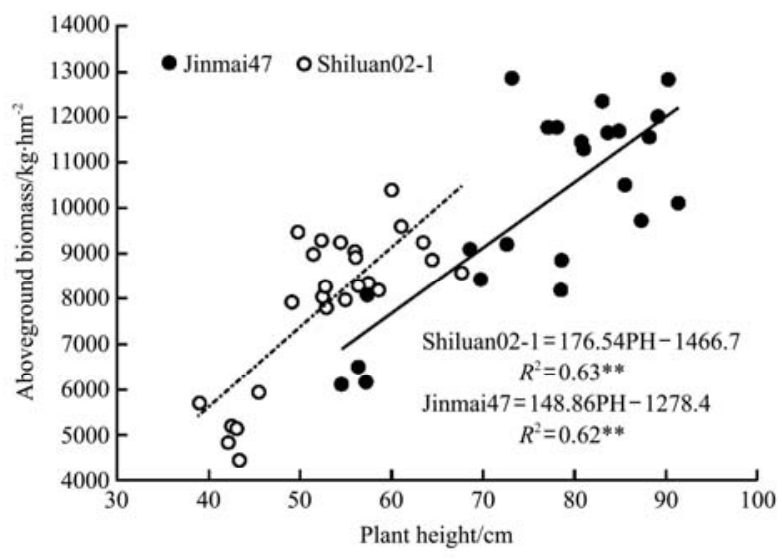

a. Aboveground biomass and plant height

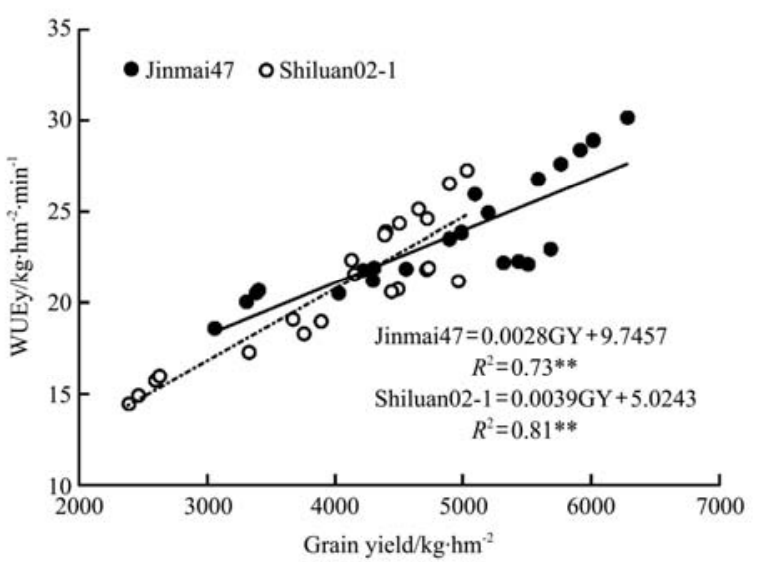

c. Grain yield and the water use efficiency in grain yield level (WUEy) Note: ** significance at a $p$ level of 0.01

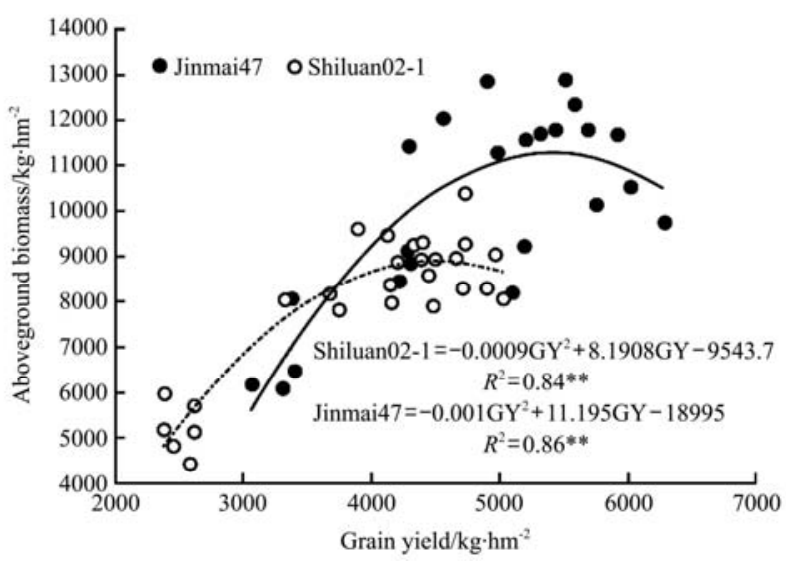

b. Aboveground biomass and grain yield

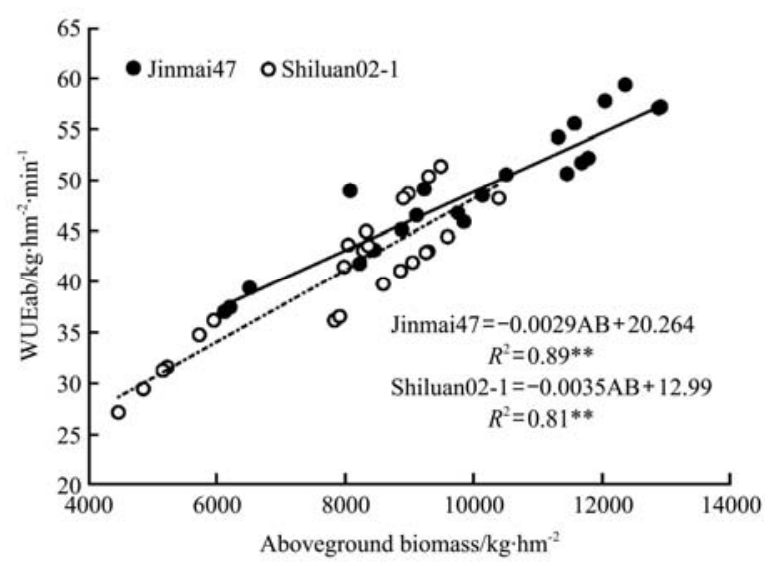

d. Grain yield and the water use efficiency in aboveground biomass level (WUEab)

Figure 6 Relationships between a. aboveground biomass and plant height; b. aboveground biomass and grain yield; c. grain yield and the water use efficiency in grain yield level (WUEy); and d. grain yield and the water use efficiency in aboveground biomass level (WUEab)

Shiluan02-1 during all the four growing seasons. The findings suggest that the drought-resistant variety has significantly higher grain yield during the dry years in the NCP. This might be related to the difference in $\mathrm{AB}$ (Table 3 and Figure $6 \mathrm{~b}$ ). Some studies have indicated that the improvement in yield is more strongly related to the biomass than $\mathrm{HI}$ among winter wheat ${ }^{[5,26,27]}$. Zhou et al. $^{[28]}$ also demonstrated that the increase in wheat yield significantly depends on the increase in $\mathrm{AB}$. Photosynthesis capacity plays an important role in increasing the production of $\mathrm{AB}$. The higher the photosynthesis capacity of flag leaf, the higher the grain yield and aboveground biomass ${ }^{[29-33]}$. In the study, Jinmai47 exhibited higher $\mathrm{AB}$ accumulation than that of Shiluan02-1 owing to higher photosynthetic capacity of leaves. Based on the correlation presented in Figure 6b, the grain yield of Jinmai47 was higher than that of Shiluan02-1. Furthermore, it was also related to the total precipitation, time of precipitation, and temperature status between the two winter wheat cultivars during the four growing seasons (Figure 2a). Under similar conditions, when compared with those of Shiluan02-1, Jinmai47 had more tillers, higher TGW (Tables 3 and 4), and lower CDMRG. This indicates that Jinmai47 was active and reproduced by growing quickly and by increasing aboveground biomass accumulation under water stress. Grain yield of the two winter wheat cultivars during the four growing seasons was in the following order: 2013-2014 > 2012-2013 > 2011-2012 > 2010-2011. This can be attributed to the higher amount of precipitation, $192.3 \mathrm{~mm}$ and $169.6 \mathrm{~mm}$ in 2012 and 2013, respectively, than that in 2010 between wheat harvest and next wheat planting season (Table 1). The results suggest that grain yield of winter wheat was at least $2515.26 \mathrm{~kg} / \mathrm{hm}^{2}$ during the dry years in the NCP. If sowing drought resistance and high-water efficiency winter varieties, grain yield can increase to $5437.96 \mathrm{~kg} / \mathrm{hm}^{2}$. With increasing water-resource crisis, there will be limited available groundwater for irrigation in the future. High drought-resistant wheat varieties can be planted during the dry years in the NCP.

\subsection{Water use efficiency across scales}

Due to increased water scarcity, it is a serious challenge for agricultural researchers to improve crop grain yield and water use efficiency through various technologies, especially under rainfed conditions ${ }^{[6,34,35]}$. Genotypic variation for WUE has been reported in durum wheat ${ }^{[16]}$. The WUE has different definitions at different levels, such as WUEy, WUEab, and WUEr, which represent the WUE of a variety in the field. Therefore, we should pay attention to it. It is well known that the WUE often strongly relates with crop drought resistance and drought tolerance ${ }^{[36]}$. There was a difference of $42.1 \%$ in the WUEy among 19 winter wheat cultivars ${ }^{[14]}$. Based on the results of the present study, this study also made a similar conclusion (Tables 4 and 5). The two winter wheat cultivars exhibited different water consumptions rates, WUEy, WUEab, and WUEr. The average WUEy, WUEab, and WUEr of the drought-resistant cultivar Jinmai47 were $22.62 \mathrm{~kg} /\left(\mathrm{hm}^{2} \cdot \mathrm{mm}\right), 47.68 \mathrm{~kg} /\left(\mathrm{hm}^{2} \cdot \mathrm{mm}\right)$ and $72.74 \mathrm{~kg} /\left(\mathrm{hm}^{2} \cdot \mathrm{mm}\right)$, respectively. They were $11.08 \%, 16.40 \%$, and $17.21 \%$ higher than those of Shiluan02-1. The WUEy of Jinmai47 was marginally higher than that of Shiluan02-1; however, WUEab and WUEr were significantly higher than those of Shiluan02-1 during 
the four growing seasons (Table 3). This indicates that drought-resistant wheat cultivars improve the WUEy by increasing $\mathrm{AB}$ and WUEab. This is consistent with the findings of Sun et al. $^{[37]}$ and Zhou et al. ${ }^{[28]}$

\subsection{Growth strategies of different wheat cultivars}

The results of the study indicate differences in response strategies between the drought-resistant and drought-sensitive winter wheat cultivars in dry years. Jinmai47 and Shiluan02-1 did not significantly differ in their water consumption during the four growing seasons except in 2013-2014 (Table 5). This suggests that the wheat cultivars with strong drought resistance increased their WUE, which did not mainly depend on the decrease in its water consumption. This is consistent with the findings of earlier studies $^{[5]}$. According to the study, Jinmai47 has high efficiency tillers, plant height, and TGW, which are associated with high flag leaf photosynthesis potential ${ }^{[23]}$. However, it has low DMRE and CDMRG. Although the AB of Shiluan02-1 was lower than that of Jinmai47 because of lower plant height, and fewer efficiency tillers or EN, the DMRE and CDMRG were significantly higher than those of Jinmai47. It indicated that there was different growth strategy for the two winter wheat cultivars under water stress conditions. Jinmai47 obtain higher grain yield mainly owing to higher $\mathrm{AB}$ than that of Shiluan02-1.

Under rainfed conditions in field, Jinmai47 exhibits high dry matter accumulation during grain filling. Under sufficient water condition, Jinmai47 grows quickly and produces many tillers to accumulate high AB. It is not only a way to gain a competitive advantage, but also a way to produce seeds for next generation when there might be water stress. The findings are in accordance with the observations of Sheng et al. ${ }^{[38]}$ and Wang et al. ${ }^{[39]}$ Sheng et al. ${ }^{[38]}$ reported that more tillers or high $\mathrm{AB}$ of drought-resistant crops is an ecological strategy for crops to adapt to fluctuations in environment ${ }^{[38]}$. Shiluan02-1, a drought-sensitive winter wheat variety, did not exhibit high growth redundancy and grain yield mainly due to high CDMRG to withstand water stress. These results demonstrate that the growth strategies of the wheat varieties differ during the dry years.

\subsection{Winter wheat planting and adjustment of cropping structure}

Optimization of cropping patterns is important for water-saving agricultural management ${ }^{[40]}$. In the NCP, winter wheat is grown from October to June next year. During this period, there is little precipitation for the growth and development of wheat ${ }^{[5]}$. To achieve high winter wheat grain yield, groundwater is exploited for irrigation, leading to its continuous decline. Measures to adjust plantation structure by reducing planting area of winter wheat have been proposed. The results revealed that the grain yield of winter wheat can reach up to $4519.05 \mathrm{~kg} / \mathrm{hm}^{2}$ with four continuous rainfed years. Precipitation after harvesting wheat can compensate soil water content before winter wheat sowing. Furthermore, wheat planting can prevent the exposure of soil and reduce the risk of sandstorms. Therefore, for environmental protection it is important to plant winter wheat. The measures of groundwater reducible exploitation should include planting drought tolerant wheat varieties under rainfed condition instead of simply reducing wheat cultivated area or prohibiting wheat planting ${ }^{[2]}$. However, some studies argue that drought-resistant winter wheat has no high capacity grain yield. In the NCP, dry year is rarer than normal year. Selecting drought-resistant winter wheat cultivars will be a risk to obtain low grain yield. Moreover, the experiments were conducted using two winter wheat cultivars in one site. Thus, drought resistance and high WUEy will be the breeding objectives in the future.

\section{Conclusions}

During the four growing seasons under rainfed conditions, the average grain yield of Shiluan02-1 was $3879.48 \mathrm{~kg} / \mathrm{hm}^{2}$. When compared with that of Shiluan02-1, the grain yield of Jinmai47 increased by $16.49 \%$. The AB of Jinmai47 was $28.68 \%, 5.59 \%$, $32.51 \%$ and $25.44 \%$ higher than that of Shiluan02-1 during the four growing seasons, respectively. The WUEab and WUEr were significantly higher than those of Shiluan02-1. The results of dry matter remobilization revealed that Jinmai47 have stronger contribution of post-heading assimilates to grain. However, the CDMRG of Shiluan02-1 was higher than that of Jinmai47. The two cultivars exhibited different adaptive strategies under drought condition. The results showed that the drought-resistant winter wheat cultivars have high tiller numbers, early vigor, and high aboveground biomass to adapt to rainfed conditions in NCP, such as Jinmai47. The results will provide valuable information on how to select wheat variety in measures of groundwater reducible-exploitation.

\section{Acknowledgments}

The present study was supported by the National Key Research and Development Program of China (2016YFD0300808), National Key Technology R\&D Program of China (2013BAD05B02), Hebei Province S\&T Project (18226419D), and National Science Foundation of China (31100191).

\section{[References]}

[1] Tari F T. The effects of different deficit irrigation strategies on yield quality, and water-use efficiencies of wheat under semi-arid conditions. Agric. Water Manage, 2016; 167: 1-10.

[2] Zhang K, Zeng Z H, Zhao J, Wang X Q, Zhou J, Xu H S, et al. Impact analysis of reduce the extraction of groundwater on wheat production in North China Plain. J Agric. Sci. Technol, 2016; 18(5): 111-117. (in Chinese)

[3] Wang Y, Xi W, Wang Z, Wang B, Xu X, Han M, et al. Contribution of ear photosynthesis to grain yield under rainfed and irrigation conditions for winter wheat cultivars in the past 30 years in North China Plain. J. Integ. Agric, 2016; 15(10): 2247-2256.

[4] Zhang Z, Zhou X B, Chen Y H. Effects of irrigation and precision planting patterns on photosynthetic product of wheat. Agron. J, 2016; 108(6): 2322-2328.

[5] Dong B, Shi L, Shi C, Qiao Y, Liu M, Zhang Z. Grain yield and water use efficiency of two types of winter wheat cultivars under different water regimes. Agric. Water Manage, 2011; 99(1): 103-110.

[6] Mei X R, Zhong X L, Vadez V, Liu X Y. Improving water use efficiency of wheat crop varieties in the North China Plain. J. Integr. Agric, 2013; 12(7): 1243-1250.

[7] Xia J, Liu M Y, Jia S F. Water security problem in North China: Research and perspective. Pedosphere, 2005; 15(5): 563-575.

[8] Sun H, Shen Y, Yu Q, Gerald N, Zhang Y, Liu C, et al. Effect of precipitation change on water balance and WUE of the winter wheat-summer maize rotation in the North China Plain. Agric. Water Manage, 2010; 97(8): 1139-1145.

[9] Wang X, Li X B, Xin L. Impact of the shrinking winter wheat sown area on agricultural water consumption in the Hebei Plain. J. Geogr. Sci, 2014 24(2): 313-330.

[10] Chen S Y, Zhang X Y, Shao L W, Sun H Y, Niu J F. A comparative study of yield, cost-benefit and water use efficiency between monoculture of spring maize and double crops of wheat-maize under rain-fed condition in the North China Plain. Chin. J. Eco-Agric, 2015; 23(5): 535-543. (in Chinese)

[11] Wang Y, Zhang Y, Zhang R, Li J, Zhang M, Zhou S, et al. Reduced irrigation increases the water use efficiency and productivity of winter wheat-summer maize rotation on the North China Plain. Sci. Total 
Environ, 2018; 618: 112-120.

[12] Farquhar G D, Richards R A. Isotopic composition of plant carbon correlates with water use efficiency of wheat. Aust. J. Plant Physiol, 1984; 11: 539-552.

[13] Shan L, Deng X P, Zhang S Q. Advance in biological water-saving research: Challenge and perspectives. Sci. Found. China, 2006; 2: 66-71.

[14] Dong B D, Zhang Z B, Liu M Y, Zhang Y Z, Li Q, Shi L, et al. Water use characteristics of different wheat varieties and their responses to different irrigation schedulings. Trans. Chin. Soc. Agric. Eng, 2007; 23(9): 27-33. (in Chinese)

[15] Zhang X, Chen S, Sun H, Wang Y, Shao L. Water use efficiency and associated traits in winter wheat cultivars in the North China Plain. Agric. Water Manage, 2010; 97(8): 1117-1125.

[16] Fulvia R, Jaleh G, Sylvie M, Loredana M, Anna M, Franz-Werner B. Constitutive differences in water use efficiency between two durum wheat cultivars. Field Crops Res, 2012; 125: 49-60.

[17] Nagy E, Lantos C, Pauk J. Selection of drought tolerant and sensitive genotypes from wheat DH population. Acta Physiol. Plant, 2017; 39(12): 261.

[18] Levitt J. Responses of plants to environmental stresses. Water, radiation, salt and other stresses: New York: Academic Press, 2015; pp. 93-128.

[19] Tomar R, Tiwari S, Vinod N B K, Chand S, Deshmukh R. Molecular and morpho-agronomical characterization of root architecture at seedling and reproductive stages for drought tolerance in wheat. PLoS One, 2016; 11(6): e0156528. doi: 10.1371/journal.pone.0156528.

[20] Xu C, Tao H, Tian B, Gao Y B, Ren J H, Wang P. Limited-irrigation improves water use efficiency and soil reservoir capacity through regulating root and canopy growth of winter wheat. Field Crops Res, 2016; 196: $268-275$.

[21] Panigrahi B, Panda S N, Raghuwanshi N S. Potato yield and water-use-efficiency under furrow irrigation. Irrigation Science, 2001; 20(4): 155-163.

[22] Wu Q H, Wang G L, Lin W J, Zhang F W. Estimating groundwater recharge of Taihang Mountain Piedmont in Luancheng County, Hebei Province, China. Geol. Sci. Technol. Inf, 2012; 31(2): 99-105. (in Chinese)

[23] Chu P, Zhang Y, Yu Z, Guo Z, Shi Y. Winter wheat grain yield, water use, biomass accumulation and remobilization under tillage in the North China Plain. Field Crops Res, 2016; 193: 43-53.

[24] Sun H, Shao L, Chen S, Wang Y, Zhang X. Effect of sowing time and rate on crop growth and radiation use efficiency of winter wheat in the North China Plain. Int. J. Plant Prod, 2013; 7(1): 117-138.

[25] Wen H Q, Zhang L S, Li S H, Hou L S, Yao X L, Yao H L, et al. Analysis of yield forming factors of wheat in arid land in Shanxi. J. Shanxi Agric.Sci, 2001; 29(1): 5-10. (in Chinese)
[26] Austin R B, Ford M A, Morgan C L. Genetic improvement in the yield of winter wheat; a further evaluation. J. Agric. Sci, 1989; 112(3): 295-301.

[27] Shearman V J, Sylvester-Bradley R, Scott R K, Foulkes M J. Physiological progress associated with wheat yield progress in the UK. Crop Sci, 2005; 45: 175-185.

[28] Zhou T, Xu K W, Liu W G, Zhang C C, Chen Y X, Yang W Y. More aboveground biomass, phosphorus accumulation and remobilization contribution to high productivity of intercropping wheat. Int. J. Plant Prod, 2017; 11(3): 407-424.

[29] Renolds M, Foulkes M J, Slafer G A, Berry P, Parry M A J, Snape J W, et al. Raising yield potential in wheat. J. Exp. Bot, 2009; 60: 1899-1918.

[30] Renolds M P, van Ginkel M, Ribaut J M. Avenues for genetic modification of radiation use efficiency in wheat. J. Exp. Bot, 2000; 51: $459-473$.

[31] Koutroubas S D, Papakosta D K, Doitsinis A. Cultivar and seasonal effects on the contribution of pre-anthesis assimilates to safflower yield. Field Crops Res, 2004; 90(2): 263-274.

[32] Lu D, Lu F, Pan J, Cui Z, Zou C, Chen X, et al. The effects of cultivar and nitrogen management on wheat yield and nitrogen use efficiency in the North China Plain. Field Crops Res, 2015; 171: 157-164.

[33] Yao H, Zhang Y, Yi X, Zuo W, Lei Z, Sui L, et al. Characters in light-response curves of canopy photosynthetic use efficiency of light and $\mathrm{N}$ in responses to plant density in field-grown cotton. Field Crops Res, 2017; 203: 192-200.

[34] Deng X P, Shan L, Zhang H, Turner N C. Improving agricultural water use efficiency in arid and semiarid areas of China. Agric. Water Manage, 2006 80(13): $23-40$.

[35] Agrawal M K, Panda S N, Panigrahi B. Modeling water balance parameters for rainfed rice. Journal of Irrigation and Drainage Engineering, 2004; 130(2): 129-139.

[36] Dong B D, Liu M Y, Shao H B, Li Q Q, Shi L, Du F, et al. Investigation on the relationship between leaf water use efficiency and physio-biochemical traits of winter wheat under rained condition. Colloids Surf. B Biointerfaces, 2008; 62(2): 280-287.

[37] Sun C Y, Dong W Q, Liu M Y, Dong B D. Research progression on water use efficiency and its difference mechanism of different crop varieties. Chin. Agric. Sci. Bull, 2009; 25(12): 117-121. (in Chinese)

[38] Sheng C F. Growth tediousness as an explanation over-compensation of crops for insect feeding. J. Appl. Ecol, 1990; 1(1): 26-30. (in Chinese)

[39] Wang J, Li P, Cheng Z, Asfa B, Lv G, Zhu Y, et al. Plant ideotype and growth redundancy in dryland wheats. Acta Ecol. Sin, 2015; 35(8): 2428-2467. (in Chinese)

[40] Hao L N, Su X L, Singh V P. Cropping pattern optimization considering uncertainty of water availability and water saving potential. Int J Agric \& Biol Eng, 2018; 11(1): 178-186. 